\title{
Grafit ve Ömrünü Tamamlamış Atık Lastikten Elde Edilen Karbon Siyahının İyileștirilmiş Hummers Yöntemi ile Oksidasyonu
}

\author{
Oxidation of the Graphite and Carbon Black Obtained From Worn Out Waste Tires Using \\ Improved Hummers Method
}

\author{
Recep Berk ALP (D), Ömer Faruk DİLMAÇ $\mathbb{D}$, Barış ŞiMŞEK (D) \\ Çankırı Karatekin Üniversitesi, Mühendislik Fakültesi, Kimya Mühendisliği Bölümü, 18100, Uluyazı, Çankırı, Türkiye
}

$\ddot{O} z$

Grafen oksidin kimyasal sentezinde grafitin yüksek maliyeti nedeni ile kömür veya karbon siyahı gibi düşük maliyetli alternatif karbon kaynakları üzerindeki çalışmalar yoğunlaşmıştır. Bu çalışmada, İyileştirilmiş Hummers yöntemi ile grafit ve ömrünü tamamlamış atık lastikten piroliz ile karbon siyahının oksidasyonu gerçekleştirilmiş̧ir. Grafen oksit (GO) ve okside karbon siyahının (CBO) ürün özellikleri yapısal kusurluluğu, karbon içeriği, özgül ısı kapasitesi - belirlenmiş ve kıyaslanmıştır. Raman desenleri ile yapılan analiz ile ömrünü tamamlamış atık lastikten piroliz ile elde edilen karbon siyahının, nano boyutta ve yüksek saflıkta karbon siyahına (ID/IG=2,66) ve grafen okside (ID/IG=1,40) karşın daha kusurlu bir yapıya sahip olduğu belirlenmiş̧tir ( $\mathrm{ID} / \mathrm{IG}=5,65)$. Buna karşın X-Ray Saçılım analizleri ile okside karbon siyahının grafen tabakalarında düzeninin grafen okside göre daha yüksek olduğu gözlemlenmiştir. Okside karbon siyahının atomik karbon içeriği 83,1\% iken grafen oksidin atomik karbon içeriği 73,0\% olarak belirlenmiştir. Bu sonuçlar okside karbon siyahının daha yüksek karbon içeriğine sahip olduğu görülmektedir. Çalışmadaki dikkat çekici sonuçlardan biri okside edilen karbon tabanlı malzemelerin özgül ısı değerleridir. Grafen oksidin, $-40^{\circ} \mathrm{C}$ ve $50^{\circ} \mathrm{C}$ arasında ölçülen tüm özgül ısı kapasitesi değerleri okside karbon siyahından yüksek olarak bulunmuştur. İyileştirilmiş Hummers yönteminde grafit yerine karbon siyahının belli miktarlarda kullanılmasının ürün özelliklerinin grafen oksitten çok uzaklaşmaması için gerekli olduğu sonucuna varılmıştır. Ayrıca, okside karbon siyahının grafen oksit ile su arıtma ve elektronik uygulamalar gibi potansiyel endüstriyel uygulamalar bakımından kıyaslanması gerektiği sonucuna varılmıştır.

Anahtar kelimeler: İyileştirilmiş Hummers Yöntemi, Grafen Oksit, Karbon Siyahı, Kimyasal Oksidasyon, Ömrünü Tamamlamış Atık Lastikler

\begin{abstract}
Due to the high cost of graphite in the chemical synthesis of graphene oxide, studies on low-cost alternative carbon sources such as coal or carbon black have intensified. In this study; oxidation of graphite and carbon black obtained by pyrolysis from worn out waste tires, was oxidized using the Improved Hummers method. The product properties - structural defect, carbon content, specific heat capacity of graphene oxide (GO) and oxidized carbon black (CBO) was determined and compared each other. When the Raman patterns are analysed, it was determined that carbon black obtained by pyrolysis from worn out waste tires has a more defective structure (ID / IG $=5.65$ ) than nano-sized and high-purity carbon black (ID / IG = 2.66) and graphene oxide ( $I D / \mathrm{IG}=1.40$ ). However, X-Ray Diffraction analyses showed that oxidized carbon black had higher regular graphene layer content than graphene oxide. While the atomic carbon content of oxidized carbon black was found as $83.10 \%$, the atomic carbon content of graphene oxide was determined as $73.10 \%$. These results show that carbon black has higher carbon content even if oxidized. One of the remarkable results in the study is the specific heat values of oxidized carbon based materials. All specific heat capacity values of graphene oxide measured between $-40^{\circ} \mathrm{C}$ and $50^{\circ} \mathrm{C}$ were found to be higher than the oxidized carbon black. In the improved Hummers method, it was concluded that the use of certain amounts of carbon black instead of graphite is necessary for the product properties not to be too far away from graphene oxide. In addition, it was concluded that oxidized carbon black should be compared with graphene oxide in terms of potential industrial applications such as water treatment and electronic applications.
\end{abstract}

Keywords: Improved Hummers Method; Graphene oxide; Carbon Black, Chemical Oxidation; Worn out Waste Tires 


\section{GíRiş}

Yüksek teknoloji ve yoğun endüstriyel üretim, katı atıklar oluşturmakta ve bu atıkların kontrolsüz ayrıştırılması ile çok büyük ölçekte çevresel problemler ortaya çıkmaktadır [1]. Çoğu gelişmiş ülkede dahi katı atıklar özellikle insan sağlığını tehdit eden bir noktaya gelmiştir [2]. Çevresel problemlere neden olan endüstriyel atıkların çeşitli alanlarda değerlendirilmesiyle çevre kirliliğine bir miktar çözüm sağlanabileceği gibi ülke ekonomisine de girdi sağlanacağ düşünülmektedir [3]. 2030 yılına kadar yılda 5000 milyon lastik düzenli olarak atık hale gelecektir [4-6]. Ömrünü tamamlamış atık lastiklerin toksik ve çözülebilir içeriğe sahip olması, bu malzemelerin depolanmasını yahut yakılmasını çevre için tehdit haline getirmektedir [7, 8]. Bu nedenle, ömrünü tamamlamış atık lastiklerin bertarafı da çevre için önemli bir problem haline gelmiştir [9, 10]. Ömrünü tamamlamış atık lastiklerin örneğin yapı malzemeleri içerisinde kullanılması bu malzemelerin doğadan kaybolmasını engellememektedir. Ömrünü tamamlamış atık lastiklerin bertaraf yöntemleri arasında piroliz teknolojisi son yıllarda öne çıkmaktadır [11]. Yakma ile karşılaştırıldığında, atık lastiğin pirolizi, yanıcı gaz, pirolitik yağ ve karbon siyahı gibi üç değerli ürünün üretilmesi ile daha çevre dostu ve ekonomik açıdan daha rekabetçi bir yöntem olarak kabul edilebilir [12]. Ayrıca, kapalı piroliz üniteleri ile tehlikeli yan ürünler azaltılabilir ve emisyon engellenebilir [13]. Yanıcı gaz yakıt olarak, pirolitik yağ motorin olarak, karbon siyahı ise plastik ve kablo sanayinde kullanılagelmektedir [13]. Karbon siyahı yüksek yüzey alanı, zengin fonksiyonel grupları ile absorban [14, 15], katalizör [16] veya dolgu maddesi olarak sanayinde kullanılmaktadır [17].

Son yıllarda karbon siyahının iletken polimer üretimi için dolgu malzemesi olarak [18], elektrokimyasal özellikleri artırmada lityum-iyon pillerde [19] ve biyosensörler de [20] kullanımı araştırmacıların ilgisini çekmektedir. Bununla birlikte karbon siyahının su itici olması, topaklaşmaya meyilli olması ve çözücüler içerisinde zayıf çözünürlügü̈ onun boya ve mürekkep gibi sektörlerde kullanımını kısıtlamaktadır [21]. Özellikle oksidasyon ile karbon siyahının yüzeyindeki oksijenli fonksiyonel gruplar artırabilir ${ }^{22}$. Böylece karbon siyahının suyu seven özelliği artırılır, boya ve mürekkep sektörleri için gerekli olan kararlı dispersiyonlar elde edilebilir [22]. Başta nitrik asit ile olmak üzere asidik oksidasyon yöntemleri karbon siyahının oksidasyonu için en çok kullanılan yöntemlerden biridir [23]. Asidik oksidasyon yöntemlerinde sodyum persülfat $\left(\mathrm{Na}_{2} \mathrm{~S}_{2} \mathrm{O}_{8}\right)$, sülfürik asit $\left(\mathrm{H}_{2} \mathrm{SO}_{4}\right)$, potasyum permanganat $\left(\mathrm{KMnO}_{4}\right)$, sodyum nitrat $\left(\mathrm{NaNO}_{3}\right)$, hidrojen peroksit $\left(\mathrm{H}_{2} \mathrm{O}_{2}\right)$ kimyasalları kullanılmıştır [24]. Yuan vd. [25] nitrik asit $\left(\mathrm{HNO}_{3}\right)$ ile karbon siyahını okside etmişler ve karbonun oksijene ağırlıkça oranının 8,64'den 2.66 değerine düştüğünü belirlemişlerdir. Numunelerin elementel analizini Taramalı Elektron Mikroskobu Enerji Yayılımlı X-Işını (SEM-EDX) kullanarak belirlemişlerdir. Amornwachirabodee vd. [24] karbon siyahının 1,25 olan ID/IG değerini (D piki yoğunluğunun G piki yoğunluğuna oranı) Hummers yöntemi kullanarak oksidasyon ile 1,56 değerine ulaştırmışlardır. Alfaè vd. [25] nitrik asit ile okside ettiği karbon siyahının, karbonun oksijene ağırlıkça oranının 167,6 değerinden 1,22 değerine düştüğünü belirlemişlerdir. Numunelerin elementel analizini "CHNSO" elementel analizör kullanarak belirlemişlerdir. ID/IG değerinde ise karbon siyahı ile okside karbon siyahı arasında bir fark belirlememişlerdir.

Novoselov ve ark. [26] tarafından mekanik pullanma yöntemi ile elde edilen tek tabakalı grafenin üstün mekanik, elektrik ve optik özellikleri [27] son yıllarda grafeni en çok araştırılan nano malzemelerden biri yapmıştır [28]. Diğer sentez yöntemlerine göre homojenitesi düşük olmasına rağmen; büyük ölçekte grafen oksidin daha düşük maliyetle üretimi için tercih edilen yöntem öncelikle Hummers yöntemi yöntemidir [29]. Daha sonra $\mathrm{NaNO}_{3}$ yerine $\left(\mathrm{H}_{3} \mathrm{PO}_{4}\right)$ fosforik asit kullanımı ile daha yeşil bir grafen oksit üretimi sağlanmış ve iyileştirilmiş Hummers yöntemi olarak anılmıştır [30]. İyileştirilmiş Hummers yöntemi ile grafen oksit üretiminde maliyeti yükselten malzeme grafittir [31]. Üretim maliyetini düşürmek içi araştırmacılar grafit yerine alternatif karbon kaynakları araştırmaktadır [32]. Bu amaçla araştırmacılar düşük kalite kömürden grafen oksidin Hummers yöntemi ile eldesi [33] ve kömür katranından alınan kok'dan modifiye Hummers yöntemi ile grafen oksit [34] eldesi üzerine çalışmışlardır. Fernández-García vd. [33] farklı katran içeren sıvı haldeki kömürden karbonizasyon ve Modifiye Hummers yöntemini içeren iki aşamalı bir yöntembilim ile grafen oksit elde etmişler ve ID/IG değerini (D piki yoğunluğunun $\mathrm{G}$ piki yoğunluğuna oranı) $<0,90$ olarak, karbonun oksijene ağırlıkça oranı ise 0.88 olarak belirlemişlerdir. Sierra vd. [34] kok'dan elde ettikleri grafen oksidin ID/ IG değerini 0,93 olarak, $\mathrm{C} / \mathrm{O}$ değerini (Karbonun oksijene atomik oranı) ise 3,5 olarak belirlemişlerdir.

$\mathrm{Bu}$ amaçla çalışmada, İyileştirilmiş Hummers yöntemi ile okside edilen karbon siyahının Raman spektroskopisi ile ID/IG değeri, X-Ray Saçılım (XRD) cihazı ile mikro yapısı, SEM-EDX analizi ile C/O değeri ve son olarak termal analiz cihazı ile özgül ısı değerleri belirlenmiştir. Çalışmanın ilk katkısı, İyileştirilmiş Hummers yöntemi ile okside edilen atık lastik kaynaklı karbon siyahının karakterizasyonu ve oksidasyon derecesinin analizidir. Çalışmanın ikinci katkısı ise ömrünü tamamlamış atık lastiklerden edilen karbon siyahının İyileştirilmiş Hummers yöntemi ile okside edilmesi durumunda ürün özelliklerinin, grafitten elde edilen grafen 
oksit özellikleri ile ne kadar benzeştiğinin saptanmasıdır. Böylece grafen oksit elde etmede grafit yerine ömrünü tamamlamış atık lastiklerden edilen karbon siyahının kullanılabilirliğinin ortaya çıkarılması amaçlanmıştır.

\section{MALZEME VE METOT}

\subsection{Malzeme}

Deneylerde karbon kaynağı olarak Merck firmasından temin edilen ekstra saf grafit (>\%99) ve Marmore Yeşil Kimya firmasından temin edilen karbon siyahı kullanılmıştır (Tablo 1). Deney sırasında sıcaklığın $5 C^{\circ}$ 'nin aşağısında tutulması için deneylerin her aşamasında Polyscience 15L soğutmalı su sirkülatörü kullanılmıştır. Merck firmasından temin edilen sülfürik asit $\mathrm{H}_{2} \mathrm{SO}_{4}(95-98 \%)$, orto-fosforik asit $\mathrm{H}_{3} \mathrm{PO}_{4}$ $(85 \%)$ ve potasyum permanganat $\mathrm{KMnO}_{4}(99 \%)$ grafitin oksidasyonu için kullanılmıştır. Metal iyonlarının uzaklaştırılması için hidroklorik ait $\mathrm{HCl}$ (37\% Sigma Aldrich) ve reaksiyonun sonlandırılması için hidrojen peroksit $\left(\mathrm{H}_{2} \mathrm{O}_{2}, 30\right.$ wt. \%) kullanılmıştır. Numunelerin termal analizi TA Instruments Q200 cihazı ile yapılmıştır. Raman spektroskopisi, SEM-EDX ve XRD analizi, Namık Kemal Üniversitesi Merkez Laboratuvarı (NABİLTEM), Afyon Kocatepe Üniversitesi Teknoloji Uygulama ve Araştırma Merkezi ve Bayburt Üniversitesi Merkezi Araştırma Laboratuvarında yapılmıştır.

Tablo 1. Karbon siyahı özellikleri

\begin{tabular}{ll}
\hline \hline ÖZELLIK & DEĞERLER \\
\hline \hline Kaynak & Ömrünü tamamlamış atık lastik \\
\hline Parçacık boyutu & $<50 \mu \mathrm{m}$ \\
\hline Yüzey alanı & $<90 \mathrm{~m}^{2} / \mathrm{g}$ \\
\hline Dökme yoğunluğu & $\sim 400 \mathrm{~kg} / \mathrm{m}^{3}$ \\
\hline $\mathrm{pH}$ & $5-9$ \\
\hline Sülfür içeriği & $<\% 1,0$ \\
\hline Kül içeriği & $<\% 0,5$ \\
\hline \hline
\end{tabular}

\subsection{Karbon siyahı ve grafitin oksidasyonu}

$120 \mathrm{ml} \mathrm{H}_{2} \mathrm{SO}_{4}$ ve $13 \mathrm{ml} \mathrm{H}_{3} \mathrm{PO}_{4}$ çözeltisine $1 \mathrm{~g}$ karbon tabanlı malzeme (grafit veya karbon siyahı) ilave edilerek manyetik karıştırıcı ile $5^{\circ} \mathrm{C}$ 'de karıştırılmıştır. Daha sonra 6 g potasyum permanganat $\left(\mathrm{KMnO}_{4}\right)$ yavaş̧̧a reaktöre eklenmiş ve reaktör sıcaklığı soğutmalı su sirkülatörü ile $5^{\circ} \mathrm{C}$ 'nin altında tutulmuştur. Çözelti sıcaklığ 1 önce $35^{\circ} \mathrm{C}$ 'ye çıkarılmış ve 2 saat daha karıştırılmıştır. Ardından ultra saf su yavaşça reaktöre eklenmiştir. Daha sonra çözelti sıcaklığ $85^{\circ} \mathrm{C}$ ye ç1karılmıştır ve 12 saat daha karıştırılan çözeltiye reaksiyonu durdurmak için \%30'luk $10 \mathrm{~mL}$ hidrojen peroksit $\left(\mathrm{H}_{2} \mathrm{O}_{2}\right)$ içeren $400 \mathrm{~mL}$ su çözeltiye eklenmiştir. Son olarak metal iyonlarının uzaklaştııılması amacı ile $100 \mathrm{ml} \mathrm{HCl} \mathrm{çözeltisi}$ $(1 / 10 \mathrm{v} / \mathrm{v})$ ilave edilmiş ve numune 3 defa yıkanarak etüvde $50^{\circ} \mathrm{C}$ 'de 24 saat kurutulmuştur. Elde edilen okside karbon siyahı (CBO) ve grafen oksit (GO) $200 \mathrm{ml}$ distile su içerisinde 3 saat ultrasonik banyoda dispers edilmiş daha sonra filtre, santrifüj işlemlerine tabi tutulmuştur [30, 35 ve 36]. Karbon siyahı (CB) ve grafit oksidasyonu için aşağıda yer alan yöntembilim uygulanmıştır (Şekil 1).
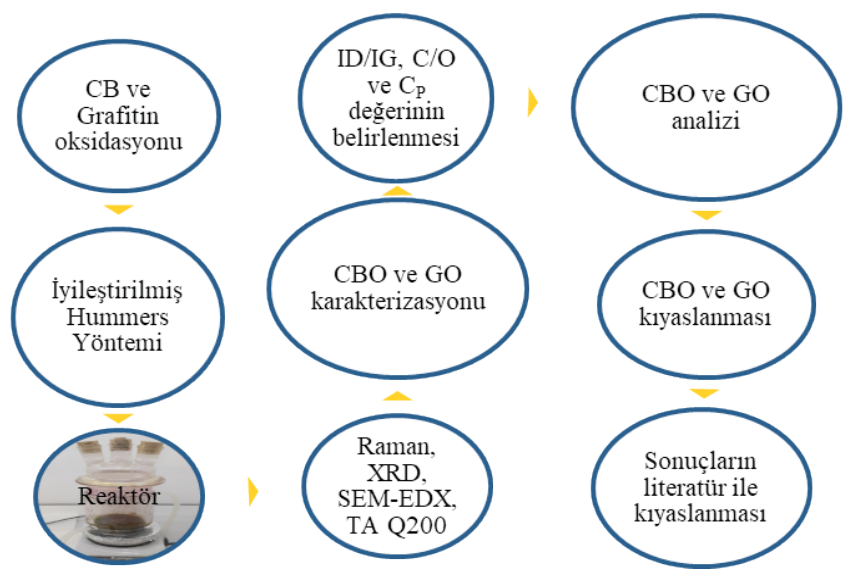

Şekil 1. Akış diyagramı

\section{BULGULAR VE TARTIŞMA}

\subsection{Spektral Analizler}

CBO ve GO numunelerin Raman spektrumları sirasıla $1350 \mathrm{~cm}^{-1}$ ' de D bandı ve $1590 \mathrm{~cm}^{-1}$ ' de G bandı göstermektedir [24, 25, 35-37]. Uyarı dalga boyu ve uyarı lazer enerjisi $532 \mathrm{~nm}$ ve $10 \mathrm{mV}$ olarak seçilmiştir. Raman deseninde D ve G bandı şiddeti GO'nun başarılı bir şekilde sentezlendiğini göstermektedir [38]. GO için ID/IG değeri 1,40 olarak belirlenmiştir ve $\mathrm{D}$ pikindeki artış nispeten ürünün kusurluluğunun fazla olduğunu göstermektedir. Beklendiği gibi GO Raman deseninde 2D piki görünmemektedir (2D piki yoğunluğunun $G$ piki yoğunluğuna oranı I2D/IG değeri 0,005 ). Özellikle kullanılan oksidanların miktarca çok olması D piki şiddetini artırmıştır (Şekil 2). CBO ile GO Raman desenleri $D$ ve $G$ bandı şiddeti arasında pek bir fark bulunmamaktadır [25]. Bununla birlikte karbon siyahının başarılı bir şekilde okside olduğunu gösteren pik 2D pikidir. Karbon siyahının Raman deseninde görülmeyen bu pik oksidasyon sırasında yayvanlaşır ve şiddeti artar [24]. CBO Raman desenindeki I2D/IG değeri 5.90 olarak belirlenmiştir ve oksidasyonun başarılı bir şekilde gerçekleştiğinin göstergesidir (Şekil 2). Ayrıca yüksek oksidasyonun göstergesi ürün kusurluluğu yani D piki şiddetidir ve CBO Raman desenindeki ID/IG değeri 5.65 olarak belirlenmiştir. 


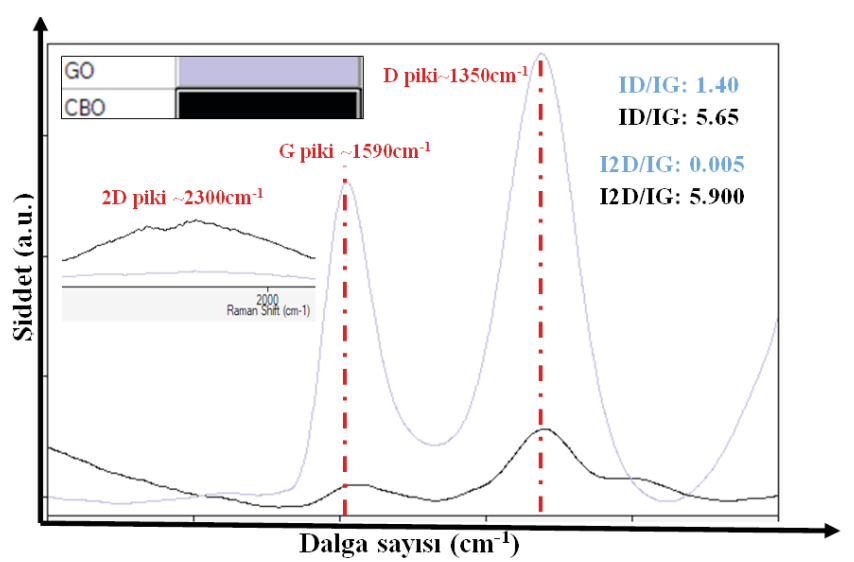

Şekil 2. CBO ve GO numunelerin Raman analizi

GO numunelerin X-Işını kırınım desenleri (XRD) incelendiğinde (002) düzlemini $10^{\circ}$ civarında oldukça şiddetli bir pik ve (100) düzlemini $42^{\circ}$ civarında zayıf bir pik göstermektedir [39] (Şekil 3). $10^{\circ}$ ve $42^{\circ}$ civarında yer alan pikler GO sentezinin başarılı olduğunu göstermektedir $[35,36]$. CBO numunelerin XRD desenleri incelendiğinde (002) düzlemini $23^{\circ}$ civarında yer alan yayvan pik ise şekilsiz karbon yapısına işaret etmektedir. Bu pikin şiddetindeki düşüklük grafen tabakalarının daha az düzenli yığıldığını göstermektedir [21]. CBO numunelerin XRD desenlerinde yer alan $43^{\circ}$ civarındaki çok şiddetli ve yayvan pik ürün kusurluluğuna işaret eder ve oksidasyonun beklenen bir sonucudur [21]. XRD desenleri hem grafit hem de karbon siyahının başarılı bir şekilde okside edildiğinin göstergesidir (Şekil 3).

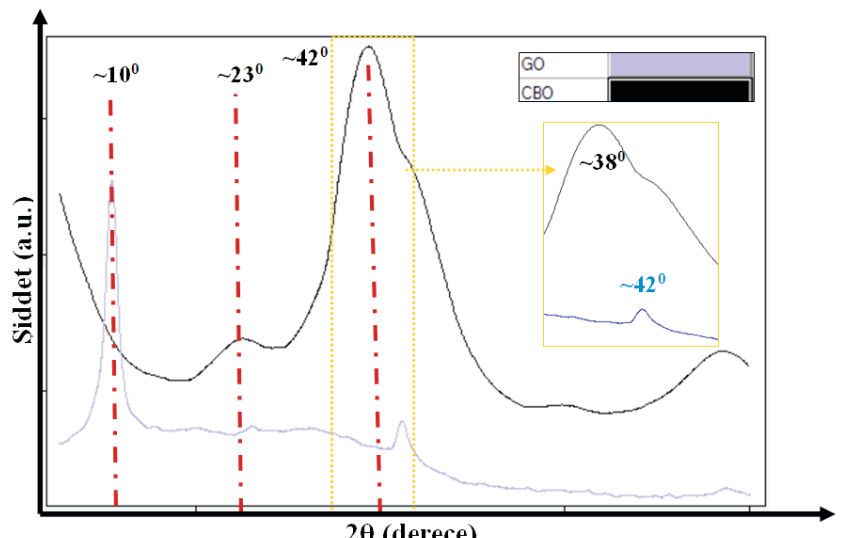

Şekil 3. CBO ve GO numunelerin XRD analizi

CBO ve GO için SEM-EDX analizleri yapılmış ve $\mathrm{C} / \mathrm{O}$ değeri 20 ve $50 \mu \mathrm{m}$ için elementel analiz yapılarak belirlenmiştir. $\mathrm{C} / \mathrm{O}$ değeri $\mathrm{GO}$ için 2,75 ve $\mathrm{CBO}$ için ise 6,15 olarak belirlenmiştir. $\mathrm{Bu}$ sonuçlar literatür ile uyumludur ve $\mathrm{CBO}$
EDX analizinde yer alan 3\%'lük silisyum, karbon siyahının yapısında bulunmaktadır.
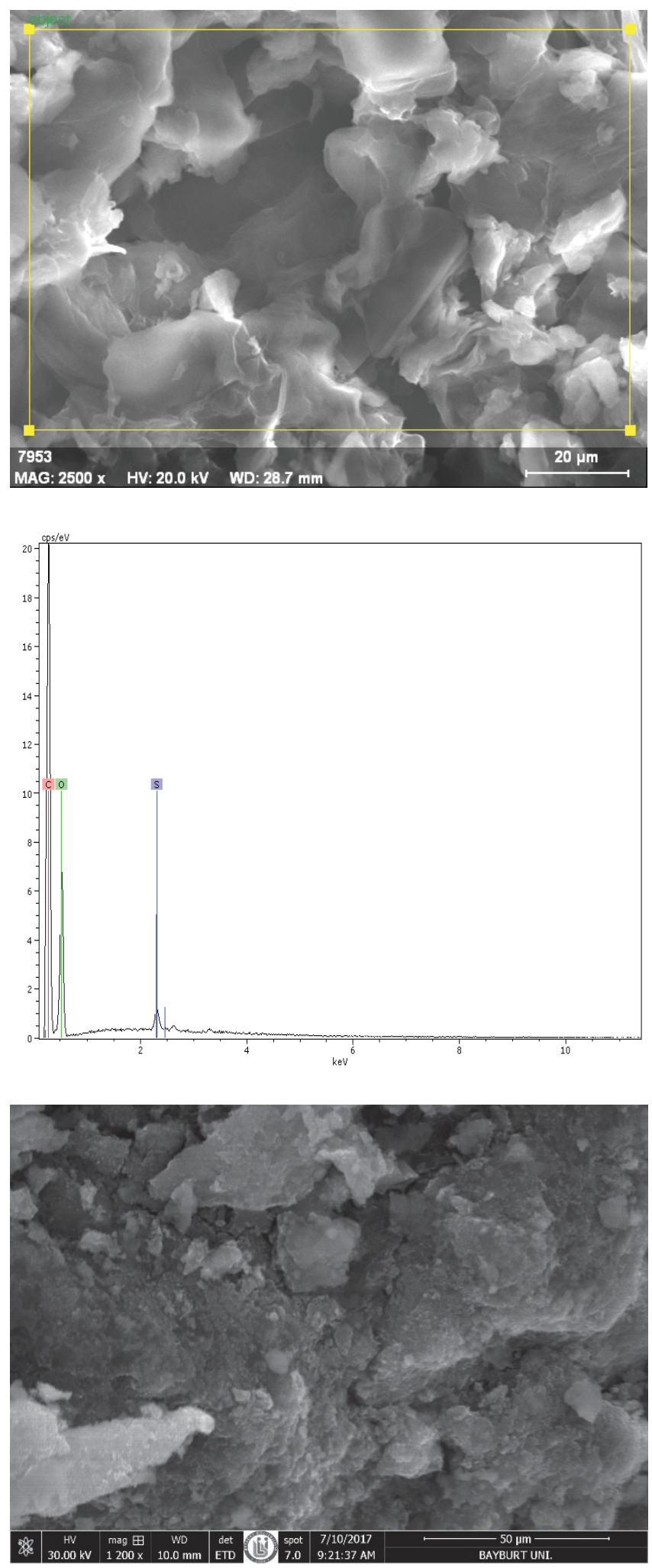


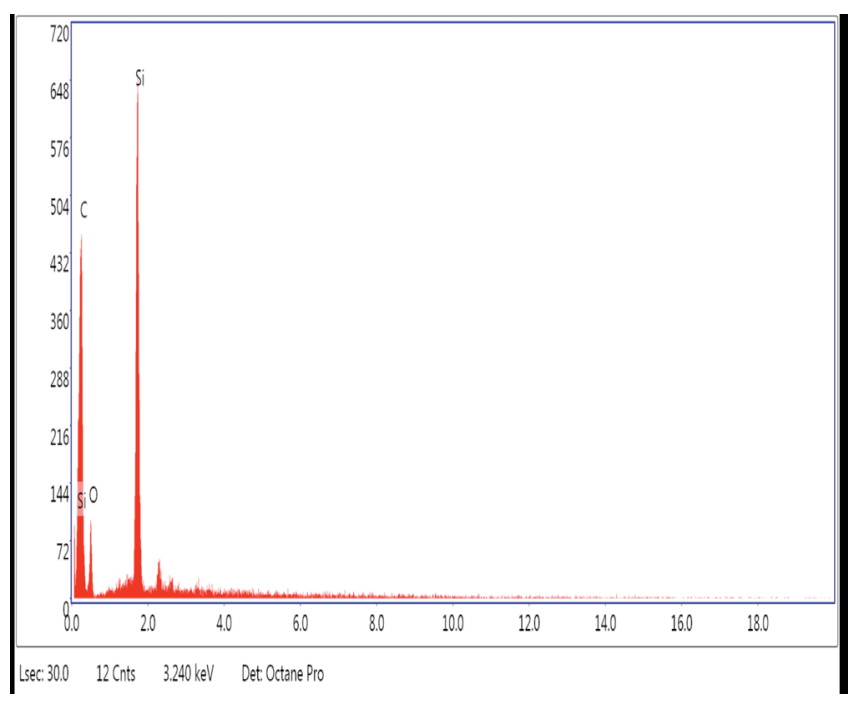

Şekil 4. GO ve CBO numunelerin SEM-EDX analizi

Özgül 1sı kapasitesi enerji depolama yeteneğinin bir ölçüsüdür [40]. $\mathrm{GO}$ ve $\mathrm{CBO}$ numunelerin termal analizleri yapılmış ve özgül ısı değerleri belirlenmiştir. GO ve CBO numunelerin oda sıcaklığında özgül ısı değerleri kıyaslandığında sırası ile 1,351 ve $0,833 \mathrm{~J} / \mathrm{g}{ }^{*}{ }^{\circ} \mathrm{C}$ değerleri elde edilmiştir (Şekil 5).

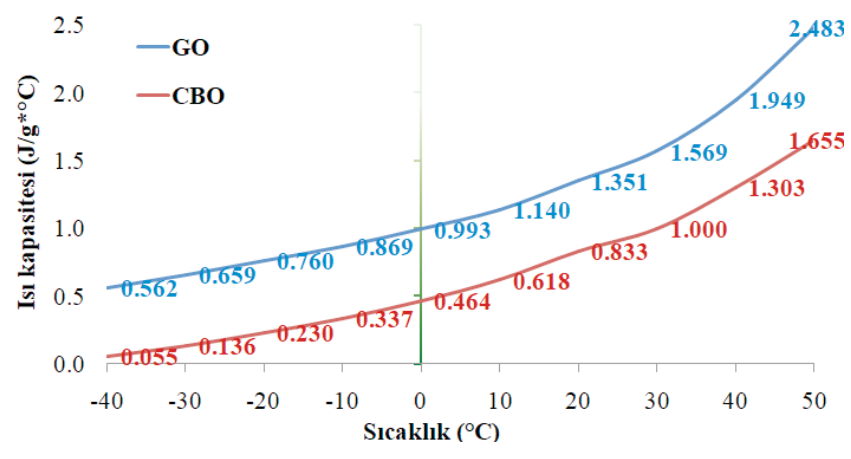

Şekil 5. GO ve CBO numunelerin 1s1 kapasiteleri

\subsection{Oksidasyon Performansının Kıyaslanması}

CBO numunesinin ID/IG değeri GO numunesinin ID/IG değerinden yaklaşık \%303 daha yüksek bulunmuştur. Karbon kaynağı olarak seçilen karbon siyahının daha yüksek ID/IG değerine sebep olduğu, bu nedenle CBO'nun daha çok yap1sal kusur içerdiği söylenebilir. İki ürünün Raman desenleri incelendiğinde GO'dan farklı olarak CBO Raman deseninde $1200 \mathrm{~cm}^{-1}$ civarında zayıf bir pik görülmektedir ve yine yapısal kusura işaret eder. XRD spektrumları kıyaslandığında CBO numunelerin (002) düzlemini $23^{\circ}$ civarında yer alan pikin GO numunelerin (002) düzlemini $23^{\circ}$ civarında yer alan pike göre daha yayvan ve şiddetli olduğu görülmektedir. GO'dan farklı olarak CBO numunelerinde $38^{\circ}$ civarında gözlenen şiddetli pikin karbonizasyon sonucu oluşan silisyum karbürden ( $\mathrm{SiC}$ ) kaynaklandığı söylenebilir. CBO'nun SEM-EDX analizinde silisyumun yer alması yine ürün için istenmeyen bir durumdur. GO ve CBO özgül 1sı değerleri kıyaslandığında GO'nun daha yüksek özgül 1sı kapasitesine sahip olduğu görülmektedir.

Çalışma sonuçları literatür ile kıyaslandığında karbon kaynağının karbon siyahı olarak tercih edildiği çalışmalara kıyasla daha kusurlu CBO elde edilmiştir. Bunun sebebi bu çalışmalarda kullanılan karbon siyahının daha saf olması ve nano boyutta olmasıdır. Bu çalışmada kullanılan ömrünü tamamlamış atık lastiklerden elde edilen karbon siyahının ID/IG değerinin literatürdeki çalışmalara yakınlığı dikkat çekicidir (Şekil 6). Benzer şekilde kullanılan ömrünü tamamlamış atık lastiklerden elde edilen karbon siyahının C/O değeri, karbon siyahı kullanılan diğer çalışmalara göre yüksektir ve sebebinin karbon siyahı saflığı olduğu düşünülmektedir. Özgül 1sı kapasitesi grafit için literatürde $20^{\circ} \mathrm{C}$ 'de $0.71 \mathrm{~J} / \mathrm{g}^{* \circ} \mathrm{C}$ civarında yer almaktadır [41]. GO ve CBO numunelerin oda sıcaklığında özgül 1sı değerleri sırası ile 1,351 ve $0,833 \mathrm{~J} / \mathrm{g}^{* \circ} \mathrm{C}$ belirlenmiştir

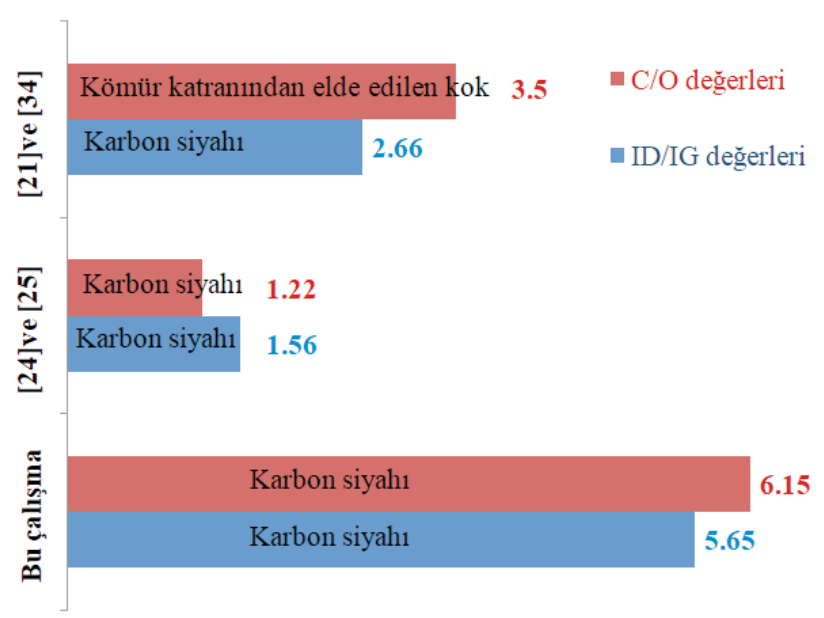

Şekil 6. ID/IG ve C/O değerleri (ID/IG and $\mathrm{C} / \mathrm{O}$ values)

\section{SONUÇLAR}

İyileştirilmiş Hummers yöntemi ile okside edilen karbon siyahının ve grafitin Raman spektroskopisi, XRD, SEM-EDX ve termal analizinin yapıldığı bu çalışmada aşağıda yer alan sonuçlar elde edilmiştir. 
1. Literatürde karbon siyahının okside edildiği çalışmalar dikkate alındığında bu çalışmada ömrünü tamamlamış atık lastikten piroliz ile elde edilen karbon siyahının başarılı bir şekilde okside edildiği belirlenmiştir. Ancak diğer çalışmalarda kullanılan nano boyutta ve saf karbon siyahına (Yuan et al. [21] ID/IG=2,66) karşın daha kusurlu bir yapıya sahip olduğu belirlenmiştir (ID/IG=5,65).

2. Çalışmadaki dikkat çekici sonuçlardan biri özgül 1s1 değerleridir. Grafen oksidin, $-40^{\circ} \mathrm{C}$ ve $50^{\circ} \mathrm{C}$ arasında ölçülen tüm özgül ısı kapasitesi değerleri okside karbon siyahından yüksektir ve bu nedenle enerji depolama çalışmalarında karbon kaynağı olarak grafitin tercih edilmesi önerilmektedir.

3. Ömrünü tamamlamış atık lastikten piroliz ile elde edilen karbon siyahının kusurlu yapıya sahip olması nedeni ile tek başına karbon kaynağı olarak grafit yerine grafen oksit üretiminde kullanılmasının yararlı olmadığı sonucuna varılmıştır. İyileştirilmiş Hummers yönteminde grafit yerine karbon siyahının belli miktarlarda kullanılmasının ürün özelliklerinin grafen oksitten çok uzaklaşmaması için gerekli olduğu sonucuna varılmıştır.

4. Ömrünü tamamlamış atık lastikten piroliz ile elde edilen karbon siyahının okside halinin hem grafit $(\mathrm{Bu}$ çalışma: $\mathrm{C} / \mathrm{O}=2,75$ ) hem de kömür katranından elde edilen kokun (Sierra et al. [34] C/O=3,5) okside haline göre daha yüksek karbon içeriğine sahip olması nedeni ile ilerideki çalışmalarda CBO'nun diğer özelliklerinin de analiz edilmesi gerektiği sonucuna varılmıştır.

5. Grafen oksit ve grafenin Brodie, Hummers, Modifiye Hummers, İyileştirilmiş Hummers veya Tour metodu gibi kimyasal yöntemler ile elde edilmesinde en yüksek maliyete sahip girdi grafit olarak görünmektedir. Elbette farklı koşullarda üretilen karbon siyahı farklı özelliklere sahip olacaktır. Oksidasyon prosesinin farklılı̆ 1 da yine okside edilmiş karbon siyahı özelliklerini değiştirecektir. Bununla birlikte grafit yerine farklı karbon kaynaklarının araştırılması bu maliyetin azaltılmasında önemli bir rol oynayacaktır.

\section{KAYNAKLAR}

[1] García-Gen, S., Sousbie, P., Rangaraj, G., Lema, J. M., Rodríguez, J., Steyer, J.-P., and Torrijos, M. (2015) Kinetic modelling of anaerobic hydrolysis of solid wastes, including disintegration processes, Waste Management 35, 96-104.

[2] Wilson, D. C., Rodic, L., Cowing, M. J., Velis, C. A., Whiteman, A. D., Scheinberg, A., Vilches, R., Masterson, D., Stretz, J., and Oelz, B. (2015) 'Wasteaware' benchmark indicators for integrated sustainable waste management in cities, Waste Management 35, 329-342.
[3] Murathan, A., Asan, A., and Abdulkarem, T. A. (2013) Çevresel Atıkların Yapı Malzemesinde Değerlendirilmesi, Journal of the Faculty of Engineering \& Architecture of Gazi University 28.

[4] Thomas, B. S., Gupta, R. C., and Panicker, V. J. (2016) Recycling of waste tire rubber as aggregate in concrete: durability-related performance, Journal of Cleaner Production 112, 504-513.

[5] Azevedo, F., Pacheco-Torgal, F., Jesus, C., Barroso de Aguiar, J. L., and Camões, A. F. (2012) Properties and durability of HPC with tyre rubber wastes, Construction and Building Materials 34, 186-191.

[6] Eiras, J. N., Segovia, F., Borrachero, M. V., Monzó, J., Bonilla, M., and Payá, J. (2014) Physical and mechanical properties of foamed Portland cement composite containing crumb rubber from worn tires, Materials \& Design 59, 550557.

[7] Wang, W.-C., Bai, C.-J., Lin, C.-T., and Prakash, S. (2016) Alternative fuel produced from thermal pyrolysis of waste tires and its use in a DI diesel engine, Applied Thermal Engineering 93, 330-338.

[8] Thomas, B. S., Gupta, R. C., Mehra, P., and Kumar, S. (2015) Performance of high strength rubberized concrete in aggressive environment, Construction and Building Materials 83, 320-326.

[9] Shu, X., and Huang, B. (2014) Recycling of waste tire rubber in asphalt and portland cement concrete: An overview, Construction and Building Materials 67, 217-224.

[10] Abbaspour, M., Aflaki, E., and Moghadas Nejad, F. (2019) Reuse of waste tire textile fibers as soil reinforcement, Journal of Cleaner Production 207, 1059-1071.

[11] Wang, M., Zhang, L., Li, A., Irfan, M., Du, Y., and Di, W. (2019) Comparative pyrolysis behaviors of tire tread and side wall from waste tire and characterization of the resulting chars, Journal of Environmental Management 232, 364-371.

[12] Dai, M., Xu, H., Yu, Z., Fang, S., Chen, L., Gu, W., and Ma, X. (2018) Microwave-assisted fast co-pyrolysis behaviors and products between microalgae and polyvinyl chloride, Applied Thermal Engineering 136, 9-15.

[13] Moulin, L., Da Silva, S., Bounaceur, A., Herblot, M., and Soudais, Y. (2017) Assessment of Recovered Carbon Black Obtained by Waste Tires Steam Water Thermolysis: An Industrial Application, Waste and Biomass Valorization 8, 2757-2770.

[14] Saleh, T. A., and Gupta, V. K. (2014) Processing methods, characteristics and adsorption behavior of tire derived carbons: a review, Advances in colloid and interface science 211, 93-101.

[15] Trubetskaya, A., Kling, J., Ershag, O., Attard, T. M., and Schröder, E. (2019) Removal of phenol and chlorine from wastewater using steam activated biomass soot and tire carbon black, Journal of Hazardous Materials 365, 846-856.

[16] Sánchez $\square$ Olmos, L., Medina $\square$ Valtierra, J., Sathish $\square$ Kumar, K., and Sánchez Cardenas, M. (2017) Sulfonated char from waste tire rubber used as strong acid catalyst for biodiesel 
production, Environmental Progress \& Sustainable Energy 36, 619-626.

[17] Feng, Z.-g., Rao, W.-y., Chen, C., Tian, B., Li, X.-j., Li, P.1., and Guo, Q.-1. (2016) Performance evaluation of bitumen modified with pyrolysis carbon black made from waste tyres, Construction and Building Materials 111, 495-501.

[18] Du, X., Zhang, Y., Pan, X., Meng, F., You, J., and Wang, Z. (2019) Preparation and properties of modified porous starch/ carbon black/natural rubber composites, Composites Part B: Engineering 156, 1-7.

[19] Wang, R., Li, W., Liu, L., Qian, Y., Liu, F., Chen, M., Guo, Y., and Liu, L. (2019) Carbon black/graphene-modified aluminum foil cathode current collectors for lithium ion batteries with enhanced electrochemical performances, Journal of Electroanalytical Chemistry 833, 63-69.

[20] dos Santos Pereira, T., Mauruto de Oliveira, G. C., Santos, F. A., Raymundo-Pereira, P. A., Oliveira, O. N., and Janegitz, B. C. (2019) Use of zein microspheres to anchor carbon black and hemoglobin in electrochemical biosensors to detect hydrogen peroxide in cosmetic products, food and biological fluids, Talanta 194, 737-744.

[21] Yuan, J. J., Hong, R. Y., Wang, Y. Q., and Feng, W. G. (2014) Low-temperature plasma preparation and application of carbon black nanoparticles, Chemical Engineering Journal 253, 107-120.

[22] Zhu, L., Lu, Y., Wang, Y., Zhang, L., and Wang, W. (2012) Preparation and characterization of dopamine-decorated hydrophilic carbon black, Applied Surface Science 258, 5387-5393.

[23] Razdyakonova, G. I., Kokhanovskaya, O. A., and Likholobov, V. A. (2015) Influence of Environmental Conditions on Carbon Black Oxidation by Reactive Oxygen Intermediates, Procedia Engineering 113, 43-50.

[24] Amornwachirabodee, K., Tantimekin, N., Pan-In, P., Palaga, T., Pienpinijtham, P., Pipattanaboon, C., Sukmanee, T., Ritprajak, P., Charoenpat, P., and Pitaksajjakul, P. (2018) Oxidized Carbon Black: Preparation, Characterization and Application in Antibody Delivery across Cell Membrane, Scientific reports 8, 2489.

[25] Alfè, M., Gargiulo, V., Di Capua, R., Chiarella, F., Rouzaud, J.-N., Vergara, A., and Ciajolo, A. (2012) Wet Chemical Method for Making Graphene-like Films from Carbon Black, ACS Applied Materials \& Interfaces 4, 4491-4498.

[26] Novoselov, K. S., Geim, A. K., Morozov, S. V., Jiang, D., Zhang, Y., Dubonos, S. V., Grigorieva, I. V., and Firsov, A. A. (2004) Electric field in atomically thin carbon films, Science 306, 666-669.

[27] Brycht, M., Leniart, A., Zavašnik, J., Nosal-Wiercińska, A., Wasiński, K., Półrolniczak, P., Skrzypek, S., and Kalcher, K. (2018) Synthesis and characterization of the thermally reduced graphene oxide in argon atmosphere, and its application to construct graphene paste electrode as a naptalam electrochemical sensor, Analytica Chimica Acta.
[28] Abdolhosseinzadeh, S., Asgharzadeh, H., and Seop Kim, H. (2015) Fast and fully-scalable synthesis of reduced graphene oxide, Scientific Reports 5, 10160.

[29] Chen, J., Yao, B., Li, C., and Shi, G. (2013) An improved Hummers method for eco-friendly synthesis of graphene oxide, Carbon 64, 225-229.

[30] Marcano, D. C., Kosynkin, D. V., Berlin, J. M., Sinitskii, A., Sun, Z., Slesarev, A., Alemany, L. B., Lu, W., and Tour, J. M. (2010) Improved Synthesis of Graphene Oxide, ACS Nano 4, 4806-4814.

[31] Korucu, H., Şimşek, B., and Yartaş1, A. (2018) A TOPSIS-Based Taguchi Design to Investigate Optimum Mixture Proportions of Graphene Oxide Powder Synthesized by Hummers Method, Arabian Journal for Science and Engineering 43, 6033-6055.

[32] Hoang, V. C., Hassan, M., and Gomes, V. G. (2018) Coal derived carbon nanomaterials - Recent advances in synthesis and applications, Applied Materials Today 12, 342-358.

[33] Fernández-García, L., Álvarez, P., Pérez-Mas, A. M., Blanco, C., Santamaría, R., Menéndez, R., and Granda, M. (2017) Peculiarities of the production of graphene oxides with controlled properties from industrial coal liquids, Fuel 203, 253-260.

[34] Sierra, U., Álvarez, P., Blanco, C., Granda, M., Santamaría, R., and Menéndez, R. (2016) Cokes of different origin as precursors of graphene oxide, Fuel 166, 400-403.

[35] Korucu, H., Şimşek, B., and Yartaş1, A. (2018) A TOPSIS-Based Taguchi Design to Investigate Optimum Mixture Proportions of Graphene Oxide Powder Synthesized by Hummers Method, Arabian Journal for Science and Engineering.

[36] Şimşek, B., Ultav, G., Korucu, H., and Yartaş1, A. (2018) Improvement of the graphene oxide dispersion properties with the use of TOPSIS based Taguchi application, Periodica Polytechnica Chemical Engineering 62, 323-335.

[37] Ferrari, A. C., Meyer, J. C., Scardaci, V., Casiraghi, C., Lazzeri, M., Mauri, F., Piscanec, S., Jiang, D., Novoselov, K. S., Roth, S., and Geim, A. K. (2006) Raman Spectrum of Graphene and Graphene Layers, Physical Review Letters 97, 187401.

[38] Skákalová, V., Kotrusz, P., Jergel, M., Susi, T., Mittelberger, A., Vretenár, V., Šiffalovič, P., Kotakoski, J., Meyer, J. C., and Hulman, M. (2018) Chemical Oxidation of Graphite: Evolution of the Structure and Properties, The Journal of Physical Chemistry C 122, 929-935.

[39] Guerrero-Contreras, J., and Caballero-Briones, F. (2015) Graphene oxide powders with different oxidation degree, prepared by synthesis variations of the Hummers method, Mater Chem Phys 153, 209-220.

[40] Ferrer, G., Barreneche, C., Solé, A., Martorell, I., and Cabeza, L. F. (2017) New proposed methodology for specific heat capacity determination of materials for thermal energy storage (TES) by DSC, Journal of Energy Storage 11, 1-6.

[41] Susanne, P., David, T. B., and Philippe, R. (2007) Determination of the specific heat capacity of a graphite sample using absolute and differential methods, Metrologia 44, 294. 